\title{
Teleskop Tutuculu Hareketli Bölümlü Protezler
}

\author{
İrem Öztürk Üçüncü(0000-0001-6585-7839) ${ }^{\alpha}$, Kadriye Funda Akaltan(0000-0001-6744-6312) ${ }^{\alpha}$
}

Selcuk Dent J, 2021; 8: 916-925 (Doi: 10.15311/selcukdentj.799029)

Bassuru Tarihi: 29 Eylü1 2020 Yayına Kabul Tarihi: 20 Ekim 2020

\begin{abstract}
öz
Teleskop Tutuculu Hareketli Bölümlü Protezler

Hareketli bölümlü protezlerde başarı ve sağ kalım, destek dokuların korunması ile mümkündür. Destek diş-implant ve dişsiz kret arasında oluşan fonksiyonel kuvvetlerin dengeli dağılımı önem kazanmaktadır. Protetik tedavilerde uygun tutucu seçiminde ağız hijyeni, anatomik durum, tutuculuk intiyacının miktarı, hekim-teknisyenin deneyimi gibi birçok faktör değerlendirilmelidir. Teleskop tutucular, kısmi dişsiz hastalarda diş veya diş - implant destekli vakaların tedavisinde başarıyla uygulanan bir tutucu türüdür. Teleskop tutuculu protezlerde çift kron tasarımı, destek yapıya simante edilen alt yapı ve hareketli proteze rijit bağlı üst yapıdan oluşmaktadır Teleskop tutucuların kullanımı ile sabit ve hareketli restorasyonların birçok avantajı elde edilebilmektedir. Bu derlemede teleskop tutucuların tipleri, avantaj-dezavantajları, üretim yöntemleri ve teleskop tutuculu protezlere ilişkin klinik değerlendirmelere yer verilecektir.
\end{abstract}

\section{ANAHTAR KELIMELER}

Teleskop tutucu, Marburg çift kron sistemi, Hareketli bölümlü protez

Hareketli bölümlü protezlerle uzun süreli başarı elde edebilmek için, destek dokuların korunması gerekmektedir. Destek diş-implant ve dişsiz kret arasında oluşan fonksiyonel kuvvetlerin dengeli dağılımı önemlidir. Restorasyonun uzun vadede başarıı olabilmesi için ağızda kalan dişlerin sayısı, konumu, periodontal durumu ve estetik beklentiler değerlendirilerek; uygun tutucular seçilmelidir. ${ }^{1}$

Protetik tedavide tutuculuk; fonasyon, estetik ve doku uyumu gibi temel faktörler arasında önemli bir yere sahiptir. ${ }^{2}$ Tutucu seçiminde; ağız hijyeni, anatomik koşullar (alt-üst çene ilişkisi, mesafesi, karşıt ark dentisyonu vb.), destekler arası mesafe, tutuculuk ihtiyacının miktarı, biyomekanik etkenler, protezin hasta tarafından rahatıkla takılıp çıkartılabilmesi, hastanın psikolojik durumu, beklentileri, sosyal statüsü ve ekonomik durumu, hekim ve teknisyenin deneyimi belirleyici faktörlerdir. Bu faktörlere ek olarak, desteklerin sayısı ve kretteki dağılımı, alveoler kretin formu ve rezorpsiyon miktarı da göz önünde bulundurulmalıdır. ${ }^{3,4}$ Teknik ve klinik prensiplerin değerlendirilmesinin yanında planlama ve endikasyon da stratejik öneme sahiptir.

Teleskop tutucular, tam dişsiz hastalarda implant destekli, kısmi dişsiz hastalarda diş veya diş - implant destekli vakaların tedavi planlamasında, 1970'ten beri

\section{ABSTRACT}

\section{Telescopic Crown-Retained Removable Partial Dentures}

Success and survival of removable partial dentures are closely related to the protection of supporting tissues. Proper stress distribution between the tooth or implant and the edentulous ridge plays an important role. Many factors, such as oral hygiene, anatomical condition, the amount of retention required, the dentist's expertise and the dental technician, should be evaluated in the selection of appropriate prosthetic retainers. Telescopic crowns are successfully used in the treatment of tooth or implant supported partially edentulous cases. In telescop retained prostheses, the double crown design consists of the primary substructure cemented to the supporting teeth or implants and the secondary structure rigidly attached to the removable prosthesis. Many advantages of fixed and removable restorations can be obtained by using telescopic retainers. In this review, the types of telescopic attachments, advantages and disadvantages, manufacturing methods and clinical assessments of telescopic partial dentures will be mentioned.

\section{KEYWORDS}

Telescopic crown, Marburg Double crown system, Removable partial denture

başarıyla uygulanan stabil bir tutucu türü olarak bilinmektedir. Teleskop tutuculu protezlerde çift kron tasarımı, destek yapıya simante edilen bir alt yapı (primer koping) ve hareketli proteze rijit bir şekilde bağlanmış uyumlu bir üst yapıdan (sekonder koping) oluşmaktadır. Üst yapı, alt yapı üzerine yerleşerek bir teleskop tutucu ünitesi meydana getirir. Alt yapı, destek dişi çürük ve termal irritasyonlardan korurken, üst yapının tutuculuk ve stabilitesi için de temel oluşturur. Kalan dentisyonla beraber hareketli yapıyla entegre bir parça olan üst yapı, protezin tutuculuğunu sağlar. ${ }^{5,6}$ Teleskop tutucular; çift kron, teleskop kron, hibrit teleskop tutuculu protezler isimleriyle de literatürde yer almaktadır.

\section{Teleskop tutuculu sistemlerin avantajları}

Teleskop tutucular, dental restorasyonlara hem sabit hem de hareketli restorasyonların birçok avantajını kazandırmaktadır. Bunlar;

- Desteklerde başarısızık gözlendiğinde protez üst yapısının yenilenmesini gerektirmeyen protez tasarımı ${ }^{5,7}$

- Destek yapıdaki açılanmaların telafi edilebilmesi ${ }^{8}$

\footnotetext{
${ }^{\alpha}$ Ankara Üniversitesi Diş Hekimliği Fakültesi, Protetik Diş Tedavisi AD, Ankara, Türkiye
} 
- Kuvvetlerin desteklerin uzun ekseni boyunca iletilmesi sayesinde, dengeli kuvvet iletimi ${ }^{9}$ (özellikle periodontal harabiyetli dişler için olumlu etki)

- Sabit protezlere benzer splintleme etkisi ${ }^{6}$

- Major ve minör bağlayıcılar olmadan yapılabilen protez tasarımı

- İlave indirekt tutucu gerekmemesi ${ }^{10}$

- Aşırı periodontal harabiyet ve alveol kret atrofisine rağmen estetik başarı

- Kolayca sağlanan oral hijyen ${ }^{6}$

- Yüksek seviyede tutuculuk ve stabilite sayesinde artan hasta konforu ${ }^{11,12}$

- Hastalar tarafından kolay takılıp, çıkarılabilme

- Psikolojik olarak hastalar tarafından tolere edilebilme ${ }^{10}$

\section{Teleskop tutuculu sistemlerin dezavantajları}

- Tedavi ve laboratuvar işlemlerinin konvansiyonel hareketli proteze göre karmaşık olması, teknik hassasiyet gerektirmesi ve yüksek maliyet ${ }^{13,14}$

- Primer ve sekonder kopingler için yeterli alan sağlamak adına daha geniş diş preparasyonuna ihtiyaç duyulması ve özellikle genç hastalarda perforasyon riskinin yüksek olması ${ }^{7}$

- Primer kopinglerin desimantasyonu ${ }^{15}$

- Parafonksiyon varlığında ve karşıt arkta doğal diş ve/veya sabit restorasyon bulunduğunda proteze daha fazla fonksiyonel kuvvet iletileceğinden tamir gerektirmesi ${ }^{15,16}$

- Uzun süreli kullanım sonrası tutuculukta azalma ve protezin yenilenmesi gereği ${ }^{10,16,17}$

- Diş kırığı riskinin yüksek olması

\section{Teleskop kron üretim yöntemleri}

Teleskop kron sistemlerinin üretilmesinde; kayıp mum tekniği, galvanoplasti, bilgisayar destekli tasarım (CAD) / bilgisayar destekli üretim (CAM) yöntemleri kullanılmaktadır. Teleskop kronlar, geleneksel olarak kayıp mum tekniği ile kıymetli veya kıymetsiz alaşımlardan üretilir. ${ }^{18}$ Primer ve sekonder kopinglerin döküm örnekleri frezeleme yöntemi ile hazırlanır. Vakaya ait alçı model üzerinde mum ile döküm örnekleri elde edilir, güdükler freze cihazında ölçümler tamamlanarak paralel konuma getirilir. Mum örnekler güdükler üzerine yerleştirilerek frezeleme işlemi ile açılandırma yapıır. Konikleşme açısı her diş için farklı seçilebilir. Mum kazıyıcı ile konik yüzeylerde $2-12^{\circ}$ açı oluşacak şekilde hazırlanır. Minimum kalınlık $0.3 \mathrm{~mm}$ olacak şekilde düzenlenir. Freze teknikleriyle teleskop tutucularda yüksek hassasiyet ve etkinlik elde edilebilir. ${ }^{5}$ Vakaya göre tercih edilen materyalden döküm elde edilir. Dökümle elde edilen primer kopingler alçı model üzerine yerleştirilerek freze cihazında aynı yöntemle mum döküm örnekler hazırlanarak sekonder kopingler istenilen materyal ile dökülür. ${ }^{19}$ Polisaj işlemleri sonrası pürüzsüz ve parlak bir yüzey elde edilir. ${ }^{20}$

Galvanoplasti işlemi, negatif yüklü katota, elektrolit çözeltisindeki metal iyonlarının çökmesi ve katot yüzeyinde saf metal bir yapının oluşmasıyla gerçekleşir.
Alt yapıya ince bir tabaka gümüş iletken uygulandıktan sonra, üst yapı elektroforming yoluyla \% 99.9 saf altından elde edilir. Bu sistemle teleskop ünitelerinin tam uyumu ve sürtünmesel tutuculuğu sağlanır. Bu yöntemin avantajları; konvansiyonel döküm metal alt yapılara kıyasla restorasyonun üstün marjinal uyumu, biyouyumluluk, metal-seramik kronlara komşu marjinal dokularda kıymetsiz alaşım ve oksit tabakasının neden olduğu koyu renklenmenin gözlenmemesi, primer ve sekonder kopingler arasındaki tükürük filminden kaynaklanan hidrolik adezyon ve olumlu sürtünmesel özelliklerdir. Ayrıca döküm sekonder kopinglerin istenen tutuculukta hazırlanması için gerekli olan teknik beceri ve zamana ihtiyaç duyulmaz. ${ }^{21-23}$ Teleskop kron sistemlerinde tam seramik primer kopinglerin, elektroforme altın sekonder kopinglerle birlikte kullanılabileceği bildirilmiştir. ${ }^{23}$ Elektroforme sekonder kopingler ile birlikte kullanılan zirkonyum primer kopinglerin, teleskop yapılar arasındaki galvanik akımı engelleyip destek yapıyı ısıya karşı koruduğu bildirilmiştir. Ancak döküme kıyasla zirkonyum koping yapısı daha hacimlidir. ${ }^{22}$

CAD / CAM sistemleri, seramik ve metal alt yapıları yanı sıra teleskop tutuculu sistemler için de kullanılabilir. ${ }^{23,24}$ Teleskop kron yapıları, CAD / CAM yöntemiyle pasif oturum sağlamak üzere hassas bir şekilde tasarlanabilir ve frezelenebilir. ${ }^{25}$ Teleskop kron üretiminde eksiltme (substractive), ekleme (additive) ve iki yöntemi birlikte kullanan CAD / CAM sistemleri mevcuttur. ${ }^{26,27}$ Eksiltme yönteminde ağız-içi tarama cihazlarıyla ya da hastaya ait ölçüden elde edilen modelin sisteme ait optik model tarayıcısı ile taranarak, 3 boyutlu model oluşturulur. CAD / CAM sistemine ait yazılım ile vakaya özgü restorasyon tasarlanır. Tasarım frezeleme cihazına aktarılarak, hazır blokların cihazın kazıyıcı ünitesine yerleştirilmesiyle üretim aşaması başlamaktadır. ${ }^{26-30}$ CAD / CAM sistemlerinde ekleme yöntemi, seçilen materyal tozlarının sıkıştırılması ile üretimdir. $\mathrm{Bu}$ sistemde elde edilen model optik tarayıc ile taranır. Model üzerine tercih edilen materyalin tozu basınç altında uygulanarak veya lazer ile birleştirilerek restorasyon üretilir. ${ }^{30}$

\section{Teleskop tutucu tipleri}

Teleskop tutucular genellikle birbirinden farklı tutuculuk mekanizmaları ile ayrılırlar. Teleskop tutucunun sayısı, açılanması ve dental arktaki dağılımı; protezin tutuculuğunu ve stabilitesini etkiler. Çok destekli bir teleskop tutuculu protezde, her teleskop kronun tutucu özelliğe sahip olması gerekmemektedir.

Teleskop tutucular; rijit, esnek ve ateşmentli teleskop tutucular olarak üçe ayrılırlar:

\section{Silindirik teleskoplar}

$\mathrm{Bu}$ tasarım üst yapının yerleştirilip çıkarılmas esnasında her iki yapı arasındaki yüzeyler arası 
sürtünmeyi esas alır. 5 Duvarlar paralel olarak hazırlanır ve piston-silindir etkisi oluşur (Şekil 1). ${ }^{19}$
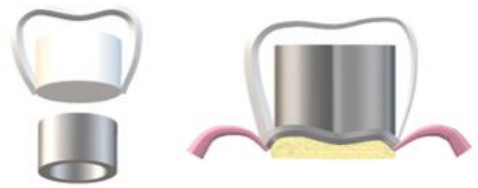

Şekil 1

Silindirik tasarımlı teleskop tutucu

\section{Konik Teleskoplar}

Konik teleskop kronlar, "kama etkisi" ile tutuculuk gösterir ve paralellik sadece primer ve sekonder kopingin temas yüzeyi arasında meydana gelir (Șekil 2). ${ }^{1,10,19}$ Kama etkisinin büyüklüğü esas olarak primer kopingin daralma açısı ile belirlenir; açı ne kadar küçükse, daha yüksek tutuculuk kuvveti oluşur. 31 Kopingler arasında $2-12^{\circ}$ arasında bir açı seçilerek, uygun bir tutuculuk ve proteze rahat bir giriş yolu sağlanabilmekle birlikte ideali $6^{\circ}$ dir. Koniklik açıSı hastaya göre belirlenmeli, destek boyu yetersiz olduğunda $2-5^{\circ}$ açı kullanılmalıdır. 5,32 Teleskop kronlardaki destek başına tutuculuk kuvvetinin 5 - 10 $\mathrm{N}$ olması tavsiye edilmiştir. Kıymetli alaşım kullanıldığında, bu değerlerin $6^{\circ}$ koniklik açıları ile sağlanabildiği bildirilmiş; kıymetsiz alaşımlar kullanıldığında ise koniklik açısının azaltılması önerilmiştir. ${ }^{31}$

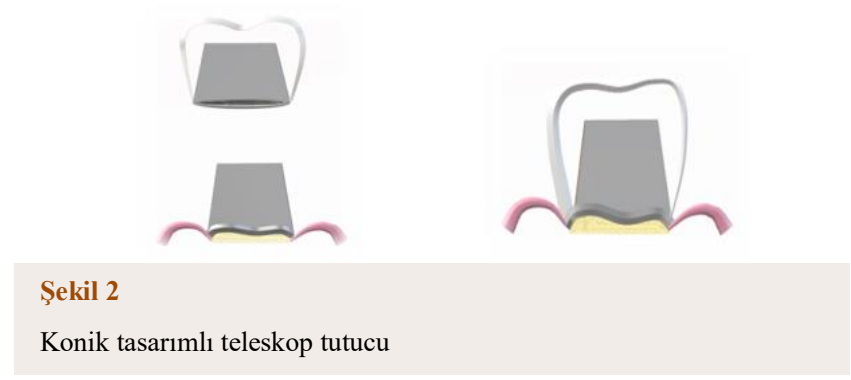

\section{Esnek Teleskop Tutucular}

Esnek teleskop kronlar, ağza yerleştirme veya çıkarma sırasında sürtünme göstermezler. Fonksiyon esnasında doku destekli hareketli protez ile destek arasında esneme oluşur ve kuvvet kırıcı etki tutucunun kendisi tarafından sağlanır. Tutucunun her iki bölümü arasındaki esneklik, primer ve/veya sekonder kopingin şekli modifiye edilerek veya aralarındaki sıkı yüzey teması kesilerek elde edilir (Şekil 3). Esnek tasarımla elde edilen dikey veya rotasyonel hareket serbestliği, hareketli protez kaidesinin destek dişlere göre esneklik göstermesini sağlar. ${ }^{1,5}$ Destek sayısı 4'ün altında olduğu durumlarda, esnek teleskop tutucuların kullanılması önerilmiştir. ${ }^{33}$ Primer kopingin tüm yüzeyleri, yüksekliklerinin yarısına kadar freze cihazında hazırlanır ve vestibül yüzeyler ile kalan okluzal yarısı konik şekillidir. Okluzal yüzde oral mukozanın esneklik miktarına bağlı olarak 0.2 - 0.5 $\mathrm{mm}$ arası bir boşluk bırakılır; mukozanın esnekliği arttıkça, boşluk miktarı da artar. Sekonder kopingin geri kalan kısmında $0.03-0.04$ mm'lik bir boşluk hazırlanır ve bu sayede sekonder koping sürtünmesiz bir dikey hareketliliğe sahiptir. Tutucunun her iki bileşeni sadece fonksiyon esnasında temas etmektedir.5

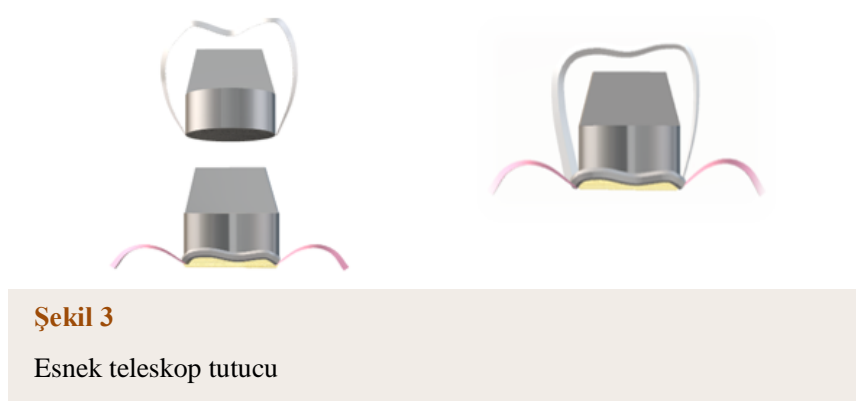

\section{Ateşmentli Teleskop Tutucular}

İlave ateşment tutucu kullanılarak tutuculuğun elde edildiği Marburg çift kron sisteminde, mükemmel uyuma sahip çift kron protezi ağıza yerleştirme ve çıkarma sırasında sürtünme göstermez. Marburg çift kron sisteminde destek olarak diş ve implantlar kullanılabilirken, uygulanması desteklerin sayısına ve konumlarına bağlı değildir. İç esnekliğe sahip bu sistem aynı zamanda rijit olarak da hazırlanabilir. Desteklere simante edilen primer kopingin sadece apikal 1/3'ü sekonder kopinge paraleldir. Sekonder koping hareketli bölümlü protezin döküm metal alt yapısının bir parçasıdır ve primer koping üzerine herhangi bir sürtünme veya kama etkisi göstermeksizin hassas bir şekilde yerleşir. Esnek tasarım, minimal bir lateral harekete, giriş yolu boyunca yumuşak ve kuvvet gerektirmeyen bir kaymaya izin verir. Bu sistemde çift krondaki mükemmel uyum; rehberlik, desteklik ve protezi yerinden çıkarıcı kuvvetlere karşı stabilite sağlarken, tutuculuk sağlamaz. Tutuculuk için TC-SNAP adı verilen bir tutucudan faydalanilır (Şekil 4). Sekonder kopingin iç yüzeyine aynı alaşımdan hazırlanmış prefabrik bir metal yer tutucu yerleştirilir veya bu boşluk hazır rezin parçalar kullanılarak döküm esnasında üretilir. Titanyum top içeren küçük elastik rezin tutucu ünite bu boşluğun içinde yer alır ve bu ünite tutuculuk azaldığı zaman kolayca değiştirilebilir. Sekonder koping ve hareketli protezin metal alt yapısı Cr-Co-Mo alaşımından döküm yoluyla hassas şekilde üretildiğinden herhangi bir lehim veya kaynak işlemine gerek kalmaz. Bu alaşımların yüksek elastik modülleri sayesinde hazırlanan metal alt yapı yüksek rijitliğe sahiptir ve ana bağlayıcı kullanılmayabilir; bu durumda üst yapılar minör bağlayıcı olarak görev yapar. 1,7 Implantlar tedavi planının parçası olduğunda, tüm metal bileşenler titanyumdan üretilebilir. ${ }^{34}$

Serbest sonlu hareketli bölümlü protezlerde kullanılan teleskop tutucular, protez kaidesinin $0.3-0.5 \mathrm{~mm}$ 'lik dikey hareketine izin vermelidir. Marburg çift kron sistemi kolayca bu hareketi sağlayacak şekilde düzenlenebilir. Primer kopingin simantasyonu ve protezin yerleştirilmesi sonrası protez kaidesi 
mukozayla temastayken primer ve sekonder koping arasında mukozanın esnekliği kadar bir boşluk bırakılır. Böylece protezin alt ve üst yapısı sadece fonksiyonel çiğneme kuvvetleri altında temas eder (Şekil 5). ${ }^{1,7}$

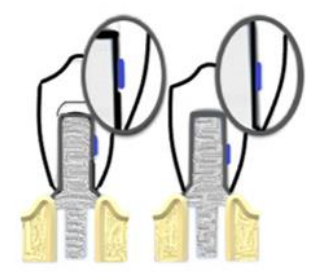

(a)

(b)

Şekil 4

Protez a) ağıza yerleştirilirken b) fonksiyondayken TC-SNAP tutuculu Marburg çift kron sistemi

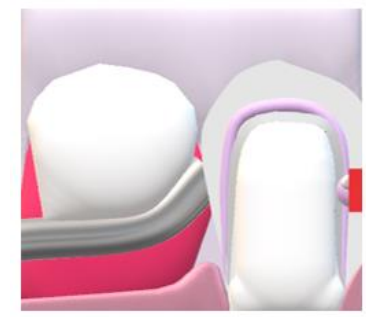

(a)

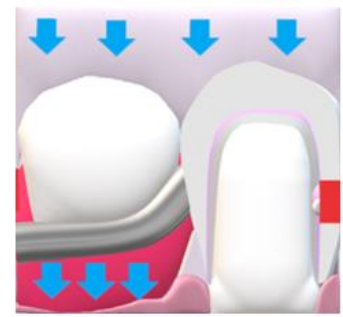

(b)
Şekil 5

Marburg çift kron sistemi. Protez a) pasif halde b) çiğneme kuvvetleri

Marburg çift kron sisteminde 4 veya daha fazla destek diş varsa rijit; 3 veya daha az sayıda destek diş varsa esnek tasarım önerilir. ${ }^{35} \mathrm{Bu}$ sistem, tüm ark restorasyon sistemidir ve çok az istisna haricinde, mevcut dişlerin tümü destek alınır. Destek dişin marjinal periodonsiyumu protez kaidesi tarafından örtülmez, bu yaklaşım perioprotektif tasarım kavramı olarak bilinir. ${ }^{1,7}$

Teleskop sistem ve konik çift kronlar için bildirilen 3.5 7 N' luk tutuculuk kuvvetleri bar ve topuz tutuculu hareketli protezler için de geçerlidir. ${ }^{36,37}$

Silindirik teleskop kron tutuculu hareketli protezlerle yapılan bir çalışmada, her bir teleskop kronun tutuculuğu ve protezlerin toplam tutuculuğu ölçülmüş; sekonder kopinglerin sadece \% 15'i, her protezin toplam tutuculuğu ölçüldüğünde ise \% 70'i ideal değerin (3.5 - $7 \mathrm{~N}$ ) üstünde çıkmıştır. ${ }^{38}$

Yapılan bir çalışmada; 21 CAD / CAM ile dizayn edilip, laser sintering yöntemiyle üretilen, üç farklı kron yüksekliğine sahip $(5,7,9 \mathrm{~mm})$ mandibular premolar diş formundaki destekler üzerine; zirkonyum ve konvansiyonel döküm yöntemiyle altın alaşımından hazırlanan primer kopingler iki farklı daralma açısına $\left(0^{\circ}\right.$ ve $\left.2^{\circ}\right)$ sahip olacak şekilde hazırlanmıştır. Tüm sekonder kopingler galvanoplasti yöntemi ile üretilmiştir. Desteklerin yüksekliği, primer koping materyali ve daralma açısının tutuculuk kuvvetleri üzerine etkisi değerlendirilmiş; zirkonyum primer kopingler, $0^{\circ}$ daralma açısına sahip grupta, özellikle kısa desteklerde, altın alaşımından daha iyi performans ve daha yüksek tutuculuk kuvvetleri göstermiştir. Uzun destekler ve $2^{\circ}$ lik daralma gösteren zirkonyum primer kopinglerin de altın alaşımlı primer kopinglere alternatif olarak kullanılabileceği bildirilmiştir. ${ }^{21}$

Benzer bir çalışmada ${ }^{19}$ üç farklı destek diş yüksekliği $(4,5,6 \mathrm{~mm})$ ile kombine edilmiş üç farklı daralma açısına $\left(2^{\circ}, 4^{\circ}, 6^{\circ}\right)$ sahip destekler arasındaki ilişki değerlendirilmiş; destek yüksekliğinin artmasının tutuculuğu arttırdığı, daralma açısındaki artışın ise tutuculuğu azalttığı bildirilmiştir. ${ }^{19}$

Teleskop kron tutuculu protez kullanan bir grup hastada oklüzyon ve tutuculuk 30 aylık takip sürecinde değerlendirilmiş ve hastaların \% 50'sinde sınırlı, \% 25'inde yeterli ve geriye kalan \% 25'inde çok iyi tutuculuk olduğu bildirilmiştir. ${ }^{39}$

\section{Teleskop tutucularda materyal seçenekleri}

Teleskop kronlarda kullanılabilen materyaller genel olarak altın alaşımları, $\mathrm{Cr}$ - Co, $\mathrm{Cr}$ - Ni alaşımı, titanyum ve tam seramiklerdir. Hastaların ekonomik durumunun yetersiz olması, hekimleri pahalı yapılar olan altın alaşımları, titanyum ve tam seramik yerine kıymetsiz metal alaşımlarına yöneltmiştir. Yapılan çalışmalarda $\mathrm{Cr}$ - Co alaşımlarının biyouyumunun $\mathrm{Cr}$ - $\mathrm{Ni}$ alaşımlardan daha iyi olduğu belirtilmiştir. ${ }^{40,41}$

Konik tam seramik primer koping ve döküm protez alt yapısında elektroforme altından yapılmış bir sekonder kopingden oluşan tasarımda, döküm metalini seramik ve elektroforme altın ile değiştirmenin, geleneksel döküm teleskop kronlara kıyasla aşınma direncini artıracağı ve böylece hareketli protezin daha sabit ve öngörülebilir bir tutuculuk kuvvetine yol açacağı bildirilmiştir. ${ }^{23,42}$

Zirkonyum esaslı primer kopingler diş renginde olmaları ve non-koroziv özellikleri sayesinde biyouyumluluklarıyla altın alaşımlara göre daha avantajlıdır ve altın alaşımlı primer kopinglere alternatif seçenek olarak bildirilmiştir. ${ }^{21,23}$

Doğal diş, implant ile doğal diş ve implant destekleri bulunan 3 ayrı hastada teleskop tutuculu ana bağlayıcısız protezler planlanmış; primer kopingler CAD / CAM ile zirkonyumdan, sekonder kopingler ise elektroforme altın alaşımdan üretilmiştir. Hastalar 3 yıllık bir süre boyunca izlenmiş, doğal dişler ve implantlar \% 100 sağkalım göstermiş ve hiçbir biyolojik, periodontal veya mekanik komplikasyon meydana gelmemiştir. ${ }^{43}$

CAD / CAM ile hareketli protezlerde zirkonyum yapılarının üretilmesinin yüksek fonksiyonel ve estetik sonuçlar sağlayabileceği gösterilmiştir. Galvanoplasti teknolojisi, yüksek biyouyumlulukta sekonder kopinglerin üretimi için tercih edilebilecek yöntemlerdendir. Bu tekniklerin ve malzemelerin 
kombinasyonu, yüksek kaliteli, mükemmel uyum ve biyouyumluluğa sahip protezlerin üretimini sağlamaktadır. ${ }^{43}$

Titanyum implantlara benzer stres dağılımına sahip, cerrahi prosedürler için potansiyel alternatif inert bir materyal olan Polietereterketon (PEEK), yüksek biyouyumluluk ve 10 yıldan fazla başarılı bir klinik geçmişe sahiptir.44,45,46 PEEK ve diğer rezin malzemeleri birleştirmek için prosedürler geliştirilmiş ve dental uygulamalar için uygun bir malzeme haline getirilmiştir. ${ }^{47}$

Yapılan çalışmalarda, hareketli bölümlü protezlerde PEEK'lerin kullanımı kroşelerle birlikte incelenmiş ve klinik uygulamalar için yeterli tutuculuk değerleri gösterilmiş; ancak PEEK esaslı teleskop kronlara ilişkin termo-mekanik yaşlanma ve CAD / CAM üretim prosedürleri ile ilgili daha uzun süreli değerlendirmelere ihtiyaç olduğu bildirilmiştir. ${ }^{48,49}$

Teleskop tutuculu protezlerle yapılan diğer klinik değerlendirmeler

\section{Stres dağılımı}

Teleskop tutuculu sistemlerde destek dişlere kuvvet iletimi, dişin uzun aksına paraleldir., ${ }^{1,50} \mathrm{Bu}$ iletim sayesinde tutucu ünite, periodontal aralıkta yoğun olarak çekme ve minimal düzeyde sıkışma kuvvetleri (yıkıcı kuvvetler) oluşturmaktadır. ${ }^{50}$

Teleskop tutucuların destek dokulara kuvvet iletimi özellikleri bakımından; çevresel kroşeler ve hassas tutucularla kıyaslandığı bir in vitro çalışmada en dengeli kuvvet iletimini sağladıkları gösterilmiştir. ${ }^{51}$

Rijit hassas tutuculu, teleskop tutuculu ve kroşe tutuculu hareketli bölümlü protezlerin destek dişlerde ve protez kaidesinde oluşturdukları streslerin karşılaştırıldığı bir çalışmada hassas tutucunun destek dişte teleskop ve kroşe tutucuya göre daha fazla stres oluşturduğu rapor edilmiş ve en yüksek başarısızlık oranı kroşe tutuculu bölümlü protezlerde saptanmıştır. Aynı çalışmada, hassas tutuculu ve teleskop tutuculu protezlerin kaidesinde oluşan stresin, kroşe tutuculu protezlere göre daha düşük olduğu belirlenmiş; hassas tutuculu protezler ile teleskop tutuculu protezlerin kaidelerine etkiyen stres oluşumu arasında fark bulunmamıştır. ${ }^{52}$

Rijit teleskop, esnek teleskop, bar, topuz ve mıknatıs tutuculu hareketli protezlerle yapılan bir çalışmada, hareketli protezler ile implant arasındaki bağlantı elemanlarının implant ve destek alveoler krete kuvvet iletimindeki etkisi araştırılmış; en yüksek moment değeri rijit teleskop tutucu için rapor edilmiştir. Esnek teleskop, topuz ve mıknatıs tutucular implantlarda en az strese neden olmuşlardır. Proteze destek alveoler kret bölgelerinde tüm tutucu sistemlerde stres bulgusu gözlenirken, en yüksek değerin esnek teleskop tutucuda olduğu ifade edilmiştir. ${ }^{53}$
Dört ve daha az destek dişe sahip, esnek, rijit ve ateşment tutuculu teleskop protezlerin destek diş ve dişsiz kretlerde neden olduğu gerilimin değerlendirildiği bir in vitro çalışmada, destek diş sayısı 2'den fazla olduğunda, tutucu tipinin ve ana bağlayıcı varlığının fark yaratmadığı görülmüştür. İki destek diş varlığında rijit teleskop tutucuların destek dişlerde esnek olanlara göre daha fazla gerilime neden olduğu gözlenmiş; ancak destek dişlerin bilateral veya unilateral olarak konumlanması gerilim farkına neden olmamıştır. ${ }^{54}$

Dişsiz maksillada simetrik ve paralel yerleştirilmiş 4 implant mevcut olduğunda, Marburg çift kron, topuz ve bar tutuculu hareketli protezleri ana bağlayıcı olmadan planlamanın mümkün olduğu, gerilim ölçer kullanılan bir in vitro çalışmayla desteklenmiştir. ${ }^{55}$

\section{Sağ kalım}

Teleskop tutuculu hareketli bölümlü protezlerin uzun dönem prognozunun, geriye kalan destek diş sayısına bağlı olduğu bildirilmiştir. 1,56 Protez için 3 destek diş ile 5 yıllık prognoz \% 90'dan \% 70'e kadar azalmış; 4 veya daha fazla destek varlığında 5 yıldan sonra \% 85'in üzerinde prognostik sağkalım oranları bildirilmiştir.1,56

Teleskop tutuculu sistem kullanılarak tedavi edilen hastalar üzerinde yapılan bir çalışmada13; destek diş sayısı, dağılımı ve rutin takip programının protezin sağkalımı üzerindeki etkisi incelenmiştir. 5 yıl sonra teleskop tutuculu sistemin sağkalımı \% 95.1, destek dişlerin sağkalımı ise \% 95.3 olarak belirlenmiştir. Protezlerin \% 26.9'u yüzey tamiri, \% 34.8'i astarlama, $\%$ 20.6'sı primer kronda yeniden simantasyon ve \% 1'i destek dişte tedavi gerektirmiştir. Destek diş sayısı sadece 1 olan restorasyonlarda sağkalım oranı \% 70.9, 2 olanlarda \% 90.4, 3 olanlarda \% 95 ve 4 olanlarda \% 97.9 olarak saptanmıştır.13

Marburg çift kron sistemi kullanılan mukoza veya diş destekli protezlerde destek dişlerin sağkalım oranı açısından anlamlı fark bulunamamıştır.7

Uzun dönem takip çalışmalarında; teleskop tutuculu protezlerin, kroşe tutuculu ve hassas tutuculu protezlere göre daha fazla sağkalım gösterdiği bildirilmiştir.57,58

Kroşe ve teleskop kron tutuculu hareketli bölümlü protezlerin prognozlarının değerlendirildiği bir retrospektif çalışmada59, her iki protez tipi ve destek dişler benzer sağkalım değerleri göstermiştir. Teleskop tutuculu sistemlerde destek dişlerde daha fazla komplikasyon görülmüş; ancak dişler vital olduğu için sorunlar tamir edilebilir düzeyde olmuştur. Her sene \% 1-3 oranında diş kaybı beklenmesine rağmen, teleskop tutuculu protezler daha iyi prognoz sergilemiştir. Buna rağmen galvanoplasti ile üretilen teleskop tutuculu sistemlerde hata yapma olasılığı yüksek olduğundan daha fazla başarısızlık 


\section{gözlenmiştir. ${ }^{59}$}

Bar ve teleskop tutuculu sistemlerin karşılaştırılığı bir çalışmada ${ }^{12}, 3$ yıllık takipte yüksek implant sağkalım ve başarı oranı (\% 100) belirlenmiştir. Protez bakım intiyacı açısından iki sistem arasında farklılık bulunmamıştır. Başka bir çalışmada ${ }^{60}$, teleskop kron veya bar sistemler ile tutuculuğu sağlanan implant destekli protezlerin başarı oranları benzer olarak bildirilmiştir.

Topuz tutuculu ve esnek teleskop tutuculu mandibular implantüstü protezlerin kıyaslandığı çalışmalarda ${ }^{61,62} 3$ yıllık takip sonunda, implant sağkalım oranları ve periimplant dokuların durumu arasında fark görülmemiştir.

Özellikle az sayıda fakat fonksiyonel destek dişlere sahip yaşlı hastalarda, uygun konumlara yerleştirilen az sayıda implant uygulaması ile teleskop tutuculu hareketli protezlerin planlanması, prognozu iyi bir tedavi seçeneği oluşturmaktadır. ${ }^{63}$ Diş ve implant desteğinin kombinasyonu sayesinde doğal destek dişlerin ve restorasyonun sağkalım oranlarının da arttırılacağı bildirilmiştir. ${ }^{62,63}$

\section{Komplikasyonlar}

Konik teleskop kronlar için en sık bildirilen komplikasyonlar; desimantasyon ve yüzey kaybıdır. Aynı yöntemle üretilen konik ve silindirik teleskop kronlar için yüzey kaybı sadece konik kronlarda bildirilmiştir. ${ }^{15}$

Apikal - marjinal periodontitis, sekonder çürükler, başarısız endodontik tedavi, progresif periodontal problemler ve diş kırıkları gibi komplikasyonlar, diş destekli teleskop tutuculu protezler için başarısızık nedenlerindendir. ${ }^{64}$

Teleskop tutuculu protezlerin 5 yıl süreyle incelendiği bir diğer çalışmada ${ }^{13}$ protezlerin \% 4.7'sinin fonksiyonunu yitirdiği, destek dişlerin \% 3.8'inin kaybedildiği saptanmış ve 5 yıl sonraki sağ kalım yüzdesi protez ve destek dişlerde \% 95 olarak bildirilmiştir. Protezlerin \% 26.9'unda faset tamiri, \% 34.8'inde astarlama, \% 20.6'sında primer kopingde yeniden simantasyon intiyacı ortaya çıkmıştır.

İmplant destekli teleskop sistemlere ait peri-implant ve inter-implant gingival hiperplazi, peri-implant mukozitis - periimplantitis gibi komlikasyonlar rapor edilmiştir. ${ }^{34,64}$

Maksiller implant destekli teleskop tutucu ve bar tutucuların kıyaslandığı bir çalışmada ${ }^{60}, 5$ - 8 yıllık takip periyodu sonunda; abutment - vida kaybı, matrix aktivasyonu - yenileme intiyacı, diş ilavesi ve kaide yenileme intiyacı her iki grup için de bildirilmiş; post operatif bakım prosedürleri ihtiyacı açısından teleskop tutuculu protezlerin daha fazla klinik işlem gerektirdiği sonucuna varımıştır. En sık olarak da kaide yenileme işlemleri uygulanmıştır.

Maksiller implant destekli teleskop, bar ve locator tutuculu sistemler kıyaslandığında, locator sisteminin, protez bakım önlemleri sıklığı, maliyeti ve protez hazırlığı kolaylığı açısından teleskop ve bar tutuculara göre üstün klinik sonuçlar verdiği sonucuna varılmıştır. ${ }^{65}$

İki implant destekli topuz ve teleskop tutuculu mandibular protezler 5 yıllık süreyle takip edilerek, topuz tutucularda gözlenen teknik komplikasyon oranının teleskop tutuculara göre daha yüksek olduğu rapor edilmiştir. ${ }^{60}$ Topuz tutuculu protezlerin, teleskop tutuculu protezlerden çok daha fazla bakım prosedürü gerektirdiği bildirilmiştir. ${ }^{66,67}$

Implant destekli protezlerin başarısının değerlendirmesinde, peri-implant krestal kemik kaybı miktarının, takip periyodunun ilk yılı sonrasında 1.5 mm'den ve sonrasında her yıl $0.2 \mathrm{~mm}$ 'den daha az olması gerektiği bildirilmiştir. Diş ve implant destekli teleskop kron sistemler için peri-implant kemik kaybı miktarı $1.62 \mathrm{~mm}$ ve sadece implant destekli teleskop kron sistemler için $1.33 \mathrm{~mm}$ olarak rapor edilmiştir. Bu sonuçlar kabul edilebilir standartlar içindedir ve dişimplant kombine protezlerin aşırı kemik rezorpsiyonuna neden olmadığını göstermektedir. ${ }^{64}$

Diş ve implant kombine teleskop sistemleri uygulanan vakalarda, destek dişlerde intrüzyon görüldüğü bildirilmiştir. ${ }^{68}$ Periodontal harabiyeti olan destek dişlerde, sağlıklı dişlere göre daha az sıklıkta intrüzyon görülmüştür. En sık görülen komplikasyonlar; doğal dişlerde intrüzyon ve implant desteklerde artmış peri-implant kemik kaybı olarak bildirilmiştir. ${ }^{69,70}$ Biyolojik komplikasyonların yanı sıra, yapım tekniklerinde karşılaşılan zorluklar nedeniyle de bu tedavi seçeneği nadiren tercih edilmektedir.

Maksiller doğal dișler ve implantlara sahip hastalarda diş ve implant destekli teleskop tutuculu protez uygulanmış ve hastalar 38 ay süresince takip edilmiştir. ${ }^{62}$ Destek doğal dişlerde kırık, endodontik tedavi intiyacı, kayıp, intrüzyon bulgularına rastlanmamış; implant desteklerde ise yüksek stabilite ve sağlıklı peri-implant yumuşak dokuları rapor edilmiştir. En sık gözlenen komplikasyon olarak, implant vida - abutment kaybı bildirilmiştir. ${ }^{62}$

\section{Hasta memnuniyeti}

Teleskop kron tutuculu ile bar tutuculu sistem arasında hasta memnuniyeti açısından anlamlı fark bulunamamıştır. ${ }^{60}$ Ancak, bu sistemler arasında seçim yapılırken mevcut restoratif alan, üretim olanakları, mevcut kemik miktarı, yerleştirilen implant sayısı, klinisyenin deneyimi ve hastanın beklentisi göz önünde bulundurulmalıdır.

Mandibular tam dişsiz hastalara yeni yapılan konvansiyonel tam protezler 3 ay süreyle kullandırımış; sonrasında interforaminal bölgeye 2 implant yerleştirilerek mevcut protezler teleskop tutuculu sisteme adapte edilmiștir. ${ }^{71}$ Hastalar, 3 aylık ve 1 ylllık periyotta takip edilmiş; konvansiyonel tam 
protezlere kıyasla ağız sağlığı ile ilgili yaşam kalitesinde, teleskop tutuculu sisteme geçilmesiyle birlikte hasta memnuniyeti ve çiğneme performansında belirgin bir artış gösterilmiştir.

\section{Hijyen/periodontal parametreler}

Bar ve teleskop tutuculu protezlerin, peri-implant ve inter-implant gingival hiperplazi, diştaşı - plak birikimi görülme insidansının değerlendirildiği çalışmalarda, bar tutuculu protezlerde teleskop sistemli protezlere kıyasla insidansın üç kat daha fazla olduğu bildirilmiştir. $\mathrm{Bu}$ durum teleskop kronların, bar tutuculardan daha kolay temizlenmesi ve bağımsız destek yapıları sayesinde protez kaidesinde daha az yer tutmalarından kaynaklanmaktadır. ${ }^{18,43,60}$

Bar ve teleskop tutuculu mandibular protezlerin değerlendirildiği bir çalışmada ${ }^{12}, 3$ yıllık takipte periimplant marjinal kemik rezorpsiyonu, cep derinliği, kanama ve gingival indeksler kıyaslanmış, her iki rijit tutuculuk sistemleri açısından farklılık gösterilmemiştir. Bununla birlikte, bar tutuculu grupta plak ve diştaşı açısından daha yüksek değerler dikkati çekmiştir.

Maksiller implantüstü teleskop, bar ve locator tutuculu protezler 3 yıllık takip sonunda karşılaştırılmış; \% 100 implant sağkalımı ve başarı oranları bildirilmiştir.60 Locator tutuculu grupta daha düşük plak, kanama, diştaşı indeks değerleri tespit edilmiş, bar tutuculu grupta diğer gruplara göre daha fazla gingival hiperplazi olgusuna rastlanmıştır. Teleskop tutuculu grupta, hasta başına yılda en fazla sayıda post operatif bakım intiyacı bildirilmiştir.

\section{SONUÇLAR}

Teleskop tutuculu hareketli protezler; az sayıda destek diş varlığı, farklı eğimlere sahip destekler, implant doğal diş desteklerinin bir arada olması gibi zor klinik şartlarda alternatif bir tedavi seçeneğidir.

Ana bağlayıcısız protez tasarımı sayesinde iyi düzeyde oral hijyen ve hasta konforu elde edilir.

Kısa klinik krona sahip $(<3 \mathrm{~mm})$ destek dişler, kötü ağız hijyeni, yüksek çürük indeksi, finansal kısıtlamalar gibi hastaya bağlı faktörler ile hekim - teknisyen tecrübesi ve teknik donanım eksikliğinde tavsiye edilmez.

Konvansiyonel dökümden, galvanoplastiye kadar değişen farklı yöntemlerle birlikte kıymetli ve kıymetsiz metal alaşımları, zirkonyum ve PEEK gibi güncel materyaller kullanılarak üretim seçenekleri arttırılabilir.

Destek diş ve/veya implant sayısına ve destek dokuların durumuna göre doğru teleskop tutucu tercihi ile yüksek sağkalım başarı oranı elde etmek mümkündür.

İleri periodontal hastalığa sahip vakalarda rijit splintleme ve dengeli kuvvet dağılımı sayesinde prognozu daha iyi restorasyonlar elde edilebilir. 


\section{KAYNAKLAR}

1. Wenz HJ, Hertrampf K, Lehmann KM. Clinical longevity of removable partial dentures retained by telescopic crowns: Outcome of the double crown with clearance fit. Int J Prosthodont 2001;14:207213.

2. Özyemişci, N. Sürtünme verniğinin altın iyon çökeltme uygulamalarının açılı teleskop kronların tutuculukları üzerine etkilerinin araştırılması. [Doktora tezi]. Ankara, Gazi Üniversitesi; 2010.

3. Pasciuta M, Grossman Y, Finger IM. A prosthetic solution to restoring the edentulous mandible with limited interarch space using an implant-tissuesupported overdenture: A clinical report. J Prosthet Dent 2005;93:116-120.

4. Trakas $T$, Michalakis $\mathrm{K}$, Kang K, Hirayama $\mathrm{H}$. Attachment systems for implant retained overdentures: A literature review. Implant Dent 2006;15:24-34.

5. Langer A. Telescope retainers and their clinical application. J Prosthet Dent 1980;44:516-522.

6. Langer $\mathrm{Y}$, Langer A. Tooth-supported telescopic prosthesis in compromised dentitions: A clinical report. J Prosthet Dent 2000;84:129-132.

7. Wenz HJ, Lehmann KM. A telescopic crown concept for the restoration of the partially edentulous arch: the Marburg double crown system. Int J Prosthodont 1998;11:541-550.

8. Preiskel HW, Tsolka P. Telescopic prostheses for implants. Int $\mathrm{J}$ Oral Maxillofac Implants 1998;13:352-357.

9. Wagner B, Kern M. Clinical evaluation of removable partial dentures 10 years after insertion: Success rates, hygienic problems and technical failures. Clin Oral Invest 2000;4:74-80.

10.Langer A. Tooth-supported telescope restorations. J Prosthet Dent 1981;45: 515-520.

11. Fukuda M, Takahashi T, Nagai H. Implantsupported edentulous maxillary obturators with milled bar attachments after maxillectomy. J Oral Maxillofac Surg 2004;62:799-805.

12. Krennmair G, Suto D, Seemann R, Piehslinger E. Removable four implant-supported mandibular overdentures rigidly retained with telescopic crowns or milled bars: A 3- year prospective study. Clin Oral Impl Res 2012;23:481-488.

13.Wöstmann B, Balkenhol $M$, Weber $A$, Ferger $P$, Rehmann P. Long-term analysis of telescopic crown retained removable partial dentures: Survival and need for maintenance. J Dent 2007;35:939-945.
14.Zafiropoulos GG, Hoffmann O. Five-year study of implant placement in regenerated bone and rehabilitation with telescopic crown retained dentures: A case report. J Oral Implantol 2009;35:303-309.

15.Behr M, Hofmann E, Rosentritt M, Lang R, Handel G. Technical failure rates of double crown-retained removable partial dentures. Clin Oral Invest 2000;4:87-90.

16. Igarashi Y, Goto T. Ten-year follow-up study of conical crown retained dentures. Int $J$ Prosthodont 1997;10:149-155.

17. Minagi S, Natsuaki N, Nishigawa G, Sato T. New telescopic crown design for removable partial dentures. J Prosthet Dent 1999;81:684-688.

18. Eitner S, Schlegel A, Emeka N, Holst S, Will J, Hamel J. Comparing bar and double-crown attachments in implant-retained prosthetic reconstruction: A follow-up investigation. Clin Oral Implants Res 2008;19:530-537.

19. Güngör MA, Artunç C, Sonugelen M. Parameters affecting retentive force of conus crowns. J Oral Rehabil 2004;31:271-277.

20.Bayer S, Stark H, Mues S, Keilig L, Schrader A, Enkling N. Retention force measurement of telescopic crowns. Clin Oral Invest 2010;14:607611.

21.Beuer F, Edelhoff D, Gernet W, Naumann M. Parameters affecting retentive force of electroformed double-crown systems. Clin Oral Investig 2010;14:129-135.

22. Uludağ B, Şahin V, Öztürk O. Fabrication of zirconium primary copings to provide retention for a mandibular telescopic overdenture: A clinical report. Int $\mathrm{J}$ Prosthodont 2008;21:509,510.

23. Weigl P, Hahn L, Lauer HC. Advanced biomaterials used for a new telescopic retainer for removable dentures. J Biomed Mater Res 2000;53:320-336.

24. Vult Von Steyern P, Carlson P, Nilner K. Allceramic fixed partial dentures designed according to the DC-Zirkon technique: A 2-year clinical study. J Oral Rehabil 2005;32:180-187.

25. Alsayed $H$, Nasser $M$, John A, Morton D. Prosthodontic rehabilitation of an ectodermal dysplasia patient with implant telescopic crown attachments. J of Prosthodont 2017;26:622-627.

26.Strub JR, Rekow D, Witkowski S. Computeraided design and fabrication of dental restorations: current systems and future possibilities. J Am Dent Assoc 2006;137:128996.

27. Karaalioğlu OF, Duymuş ZY. Diş hekimliğinde uygulanan CAD/CAM sistemleri. Atatürk Üniversitesi Diş Hekimligi Fakültesi Dergisi 2008;18(1):25-32. 
28. Yöndem İ, Aykent F. Bilgisayar desteği ile hazırlanan dental seramikler (CADICAM). Hacettepe Diş Hekimliği Fakültesi Dergisi 2008;32(3):79-86.

29. Uzun G. An overwiev of dental CAD/CAM systems. Biotechnol \& Biotechnol 2008;22(1):530-5.

30. Miyazaki T, Hotta Y, Kuriyama S, Tamaki Y. A review of dental CAD/CAM: current status and future perspectives from 20 years of experience. Dent Mater J 2009;28(1): 44-56.

31.Körber $\mathrm{KH}$. Cone crowns - A physically defined telescopic system. Einführung in Klinik und Technik 1988;22:619-630.

32. Besimo $\mathrm{CH}$, Graber G, Fluhler M. Retention force changes in implant - supported titanium telescope crowns over long-term use in vitro. J Oral Rehabil 1996;23:372-378.

33. Prakash V, Parkash H, Gupta R. Fixed removable prosthesis employing Marburg double crown system. J Indian Prosthodont Soc 2008;8:59-62.

34.Frisch E, Ziebolz D, Ratka-Kruger P, Rinke S. Double crown-retained maxillary overdentures: 5 -year followup. Clin Implant Dent Relat Res 2015;17:22-31.

35. Wenz HJ, Hertrampf K, Lehmann KM. Effects of the type and rigidity of the retainer and the number of abutting teeth on stress distribution of telescopicretained removable partial dentures. J Dent Science 2012;7:7-13.

36. Becker $H$. Retention mechanism of telescopic crowns. Zahnarztl Prax 1983;34:281-284.

37. Botega DM, Mesquita MF, Henriques GE, Vaz LG. Retention force and fatigue strength of overdenture attachment systems. J Oral Rehabil 2004;31:884-889.

38.Stancic I, Jelenkovic A. Retention of telescopic denture in elderly patients with maximum partially edentulous arch. Gerodontology 2008;25:162-167.

39. Molin M, Bergman B, Erikson A. A clinical evaluation of conical crown retained dentures. J Prosthet Dent 1993;70:251-256.

40.Ciszewski A, Baraniak M, Urbanek M. Corrosion by galvanic coupling between amalgam and different chromium-based alloys. Dent Mater 2007;23:12561261.

41.Karov J, Hinberg I. Galvanic corrosion of selected dental alloys. J Oral Rehabil 2001;28:212-219.

42.Rinke S, Buergers R, Ziebolz D, Roediger M. Clinical outcome of double crown-retained implant overdentures with zirconia primary crowns. J Adv Prosthodont 2015;7:329-337.
43.Zafiropoulos GG, Rebbe J, Thielen U, Deli G, Beaumont C, Hoffmann O. Zirconia removable telescopic dentures retained on teeth or implants for maxilla rehabilitation: Three-year observation of three cases. J Oral Implantol 2010;36:455-465.

44. Kurtz S, Devine J. PEEK biomaterials in trauma, orthopedic and spinal implants. Biomater 2007;28:4845-4869.

45.Schwitalla AD, Abou-Emara M, Spintig T. Finite element analysis of the biomechanical effects of PEEK dental implants on the peri-implant bone. $J$ Biomech 2015;48:1-7.

46.Toth JM, Wang M, Estes BT. Polyetheretherketone as a biomaterial for spinal applications. Biomaterials 2006;27:324-334.

47.Zoidis P, Papathanasiou I, Polyzois G. The use of a modified poly-etherether-ketone (PEEK) as an alternative framework material for removable dental prostheses. A clinical report. Int J Prosthodont 2016;25:580-584.

48. Tannous F, Steiner M, Shahin R. Retentive forces and fatigue resistance of thermoplastic resin clasps. Dent Mater 2012;28:273-278.

49. Wagner C, Stock V, Merk S, Schmidlin PR, Ross $M$, Eichberger M. Retention load of telescopic crowns with different taper angles between cobalt-chromium and polyetheretherketone made with three different manufacturing processes examined by pull-off test. J Prosthodont 2018;27:162-168.

50. Isaacson GO. Telescope crown retainers for removable partial dentures. J Prosthet Dent 1969;22:436-448.

51.Pezzoli M, Rossetto M, Calderale PM. Evaluation of load transmission by distal-extension removable partial dentures by using reflection photoelasticity. J Prosthet Dent 1986;56:329.

52. Saito M, Miura Y, Notani K, Kawasaki T. Stress distribution of abutments and base displacement with precision attachment and telescopic crownretained removable partial dentures. J Oral Rehabil 2003;30:482-487.

53. Heckmann SM, Winter W, Meyer M, Weber HP, Wichmann MG. Overdenture attachment selection and the loading of implant and denturebearing area. Part 2: A methodical study using five types of attachment. Clin Oral Implants Res 2001;12:640-647.

54.Şahin V, Akaltan F, Parnas L. Effects of the type and rigidity of the retainer and the number of abutting teeth on stress distribution of telescopicretained removable partial dentures. J Dent Science 2012;7:7-13.

55. Kazokoğlu Ş, Akaltan F. Strain characteristics of Marburg double crown-retained implant overdentures compared with bar and ballretained implant overdentures, with and without a rigid major connector. J Prosthet Dent 2014;112:1416-1424. 
56. Heners $M$, Walther $W$. Frequency and risk of abutment loss after insertion of conical crownretained bridges [abstract]. Int $\mathrm{J}$ Prosthodont 1999;12:452.

57. Beschnidt SM, Chitmongkolsuk S, Prull R. Telescopic crown-retained removable partial dentures: Review and case report. Compend Contin Educ Dent 2001;22:927- 942.

58. Rammelsberg P, Bernhart G, Lorenzo Bermejo J, Schmitter M, Schwarz S. Prognosis of implants and abutment teeth under combined tooth-implantsupported and solely implant-supported doublecrown-retained removable dental prostheses. Clin Oral Implants Res 2014;25:813-818.

59. Ishida K, Nogawa T, Takayama Y, Saito M, Yokoyama A. Prognosis of double crown-retained removable dental prostheses compared with clasp-retained removable dental prostheses: A retrospective study. J Prosthodont Res 2017;61:268-275.

60.Zou D, Wu Y, Huang W, Wang F, Wang S, Zhang Z. A 3-year prospective clinical study of telescopic crown, bar and locator attachments for removable four implant supported maxillary overdentures. Int $\mathrm{J}$ Prosthodont 2013;26:566-573.

61.Gotfredsen K, Holm B. Implant-supported mandibular overdentures retained with ball or bar attachments: A randomized prospective 5-year study. Int $\mathrm{J}$ Prosthodont 2000;13:125-130.

62. Krennmair $G$, Krainhofner $M$, Waldenberger $O$, Piehslinger E. Dental implants as strategic supplementary abutments for implant tooth supported telescopic crown retained maxillary dentures: A retrospective follow-up study for up to 9 years. The Int J Prosthodont 2007;20:617-622.

63. Hug S, Mantokoudis D, Mericske-Stern R. Clinical evaluation of 3 overdentures concept with tooth roots and implants: 2-year results. Int $\mathrm{J}$ Prosthodont 2006;19:236-243.

64.Lian M, Zhao K, Feng Y, Yao Q. Prognosis of combining remaining teeth and implants in double crown-retained removable dental prostheses: A Systematic Review and Meta-Analysis. Int J Oral Maxillofac Implants 2018;33:281-297.

65. Krennmair G, Seemann R, Weinlander M, Piehslinger E. Comparison of ball and telescopic crown attachments in implant-retained mandibular overdentures: A 5-year prospective study. Int J Oral Maxillofac Implants 2011;26:598-606.
66. Timmerman R, Stoker GT, Wismeijer D, Osterveld $\mathrm{P}$, Vermeeren JI, Van Waas MA. An eight-year follow-up to a randomized clinical trial of participant satisfaction with three types of mandibular implant-retained overdentures. J Dent Res 2004;83:630-633.

67. Van Kampen F, Cune M, Van Der Bilt A, Bosman $F$. Retention and postinsertion maintenance of bar-clip, ball and magnet attachments in mandibular implant overdenture treatment: An in vivo comparison after 3 month of function. Clin Oral Implants Res 2003;14:720-726.

68. Cordano L, Ercoli C, Rossni C, Torsello F, Feng C. Retrospective evaluation of complete-arch fixed partial dentures connecting teeth and implant abutments in patients with normal and reduced periodontal support. J Prosthet Dent 2005;94:313-320.

69.Baron M, Haas R, Baron W, Mailath-Pokorny G. Peri-implant bone loss as a function of toothimplant distance. Int J Prosthodont 2005;18:427433.

70.Schlumberger TL, Bowley JF, Maze GI. Intrusion phenomenon in combination tooth-implant restorations: A review of the literature. J Prosthet Dent 1998;80:199-203.

71.Yunus N, Saub R, Ali T, Salleh N, Baig M. Patientbased and clinical outcomes of implant telescopic attachment-retained mandibular overdentures: A 1-year longitudinal prospective study. Int $\mathrm{J}$ Oral Maxillofac Implants 2014;29:1149-1156.

Yazışma Adresi:

Kadriye Funda AKALTAN

Ankara Üniversitesi

Diş Hekimliği Fakültesi

Protetik Diş Tedavisi AD,

Ankara, Türkiye

E-mail : akaltanfunda@gmail.com 